\title{
The Pattern of EDTA-Blood Photo Spectrum in Ovarian Cancer Patients: A Novel Biomarker
}

\author{
Ngadikun ${ }^{\# 1}$, Untung Widodo*, Tasmini ${ }^{\# 2}$, Heru Pradjatmo ${ }^{+}$, Ahmad Hamim Sadewa $^{\# 3}$, \\ Kuncoro Asih Nugroho\& \\ ${ }^{\#}$ Department of Biochemistry, Faculty of Medicine, Universitas Gadjah Mada, Yogyakarta, Indonesia \\ E-mail: ${ }^{\# 1}$ ngadikun@ugm.ac.id; ${ }^{\# 2}$ ts_tasmini@yahoo.co.id; ${ }^{\# 3}$ hamdewa@yahoo.com \\ "Department of Anesthesia and Intensive Care, Faculty of Medicine, Universitas Gadjah Mada, Yogyakarta, Indonesia \\ E-mail: untungwdd@ugm.ac.id \\ ${ }^{+}$Department of Obstetrics Gynecology, Faculty of Medicine Universitas Gadjah Mada Yogyakarta, Indonesia \\ E-mail:herupradjatmo@gmail.com \\ ${ }^{\&}$ Department of Physics Education, Faculty of Mathematics and Natural Sciences Yogyakarta State University, Indonesia \\ E-mail: kuncornugroho@uny.ac.id
}

\begin{abstract}
One of the main causes of women's cancer-related death is Epithelial Ovarian Cancer (EOC). A new spectrophotometric method was developed to determine a biomarker for EOC. This study aims to investigate the pattern of EDTA-blood photo spectrum in EOC patients. One ml blood was collected from sixty-six subjects (33 EOC patients, 33 healthy controls) by venipuncture, which then drawn into EDTA tubes for photo spectrum analysis. The t-test using programming in Matrix Laboratory (MATLAB) for Windows 7 tested the differences in ENBS and EBS parameters in the two groups and the parameters of EDTA-blood photo spectrum in two groups based on the energetics of non-biological systems (ENBS) and energetics of biological systems (EBS) approach. The statistical significance of $\mathbf{p}<0.01$ was taken to evaluate the difference. The receivers operating characteristic (ROC) curves were applied to evaluate the effect of biomarkers on these parameters. The area under the ROC curve (AUC) is used to evaluate the biomarker with the correspondence interval (CI) of $95 \%$. The t-test results indicate that the significant difference was observed between EOC patients and healthy controls only in parameter-1 of the parameters based on the ENBS approach. However, there were significant differences in all parameters based on the EBS approach. In a training dataset, the AUC values were 0.663 , 0.704 , $0.546,0.611,0.619$, and 0.676 for ideal parameter-1 to 6 (IP1-6); and $0.886,0.855,0.765,0.909,0.897$, and 0.789 for real parameter-1 to 6 (RP1-6). Sensitivity and specificity of IP1-6 $=48.5 \%, 42.4 \%, 24.2 \%, 57.6 \%, 84.8 \%$, and $60.6 \%$; and $100.0 \%, 100.0 \%, 97.0 \%$, $66.7 \%, 39.4 \%$, and $72.7 \%$ respectively, at cut-off point $1.0 \mathrm{E}-12,-1.3 \mathrm{E}-06,3.2 \mathrm{E}-01,7.2 \mathrm{E}-11,-2.7 \mathrm{E}-05$, and $4.5 \mathrm{E}+00$ respectively; whereas sensitivity and specificity of $\mathrm{RP1}-6=100.0 \%, \mathbf{1 0 0 . 0 \%}, \mathbf{8 4 . 8 \%}, \mathbf{1 0 0 . 0 \%}, \mathbf{1 0 0 . 0 \%}$, and 93.9\%; and 93.9\%, 90.9\%, $81.8 \%$, $100.0 \%, 97.0 \%$, and $81.8 \%$ respectively, at cut-off point 5.0E-04, 6.3E-04, $-1.1 \mathrm{E}-03,9.4 \mathrm{E}-03,-8.8 \mathrm{E}-03$, and 9.8E-03 respectively. Thus, it could be concluded that parameters of the pattern of EDTA-blood photo spectrum based on the ENBS approach could be used to identify new biomarkers of EOC.
\end{abstract}

Keywords—biomarker; EBS approach; EOC; the pattern of photo spectrum.

\section{INTRODUCTION}

The World Health Organization (WHO) reports that 150,000 deaths from epithelial ovarian cancer (EOC) worldwide, there are around 22,000 new cases each year [1]. This cancer is "the most lethal gynecologic cancer." The condition will be even worse if the patient is not diagnosed at an early stage [2]. In Indonesia, ovarian cancer is the third cause of death for women, in which 829 cases have been reported [3]. The gold standard for ovarian cancer is a biopsy that confirms the presence of neoplastic cell growth in the ovary. However, it can cause bleeding and infection due to needle insertion. The CA125 is a specific biomarker for ovarian cancer especially used to monitor therapy. The level increases in the early stadium of ovary cancer [4]. This increase is by the presence of malignancy in the ovary. The CA125 is a carbohydrate antigen with a negative charge due to the presence of terminal sialic acid residues [5]. Besides CA125, fibrinogen level in the blood increases in patients with malignancy. Fibrinogen plays an important role in the 
coagulation process [6]. The CA125 and fibrinogen contribute to cellular interactions in the blood.

Erythrocytes stick together and move toward the bottom of the container (sedimentation occurs) when anti-coagulated blood is allowed to stand quietly [7]. The process is commonly known as a rouleaux formation. Ethylene Diamine Tetra Acetic Acid (EDTA) is the common anticoagulant. This molecule affects the activity of the dissolved protein in plasma so that the occurrence of coagulation of erythrocytes can be prevented [8]. The erythrocyte sedimentation rate (ESR) depends on many factors, such as the level of plasma proteins that increase the rouleaux formation and the subsequent surface-to-volume ratio that favourserythrocyte sedimentation [9], [10].

The Westergren method is a commonly used ESR measurement. This method is done by measuring the boundary between clear plasma and red corpuscles, which is the boundary between clear areas in the blood given anticoagulants (plasma regions) with cloudy areas (corpuscles) after being left on the Westergren pipette for 1 hour. Despite its relatively low sensitivity and specificity in monitoring disease activity, the ESR assessment is a widely used, cost-effective and simple test, which may be a viable alternative to novel [11]. The spectrometry method can also be used to determine the ESR value by detecting changes in clarity in the upper part of blood-EDTA in a time series [12].

Statistically, data in time series can be divided into deterministic and stochastic components, which do not correlate with each other. Ordinary differential equations are used in deterministic approaches, based on the phenomenological law of mass action. However, in complex systems, systems whose changes occur randomly, deterministic approaches cannot be used, but the approach used is a stochastic model. Stochastic models, however, are more difficult to use for analysis than deterministic models [13]. This study aims to discover the parameters of the pattern of EDTA-blood photo spectrum in EOC patients by using a new approach based on the characteristics of the living system. The existing method is that the biomarker has to be isolated such that the biomarker with low concentration may not be observed, whereas in this new method, the biomarker need not be isolated. Hence, any small concentration of the biomarker suffices because it gives an effect to the erythrocyte interactions.

\section{MATERIALS AND METHODS}

\section{A. Materials}

The study included 33 EOC patients diagnosed by the Gynecology Group and 33 healthy volunteers. The sample size is determined using the following equation [14]:

$$
n_{1}=n_{2}=\frac{\left(z_{\alpha / 2}+z_{\beta}\right)^{2} \times 2 \sigma^{2}}{\left(\mu_{2}-\mu_{2}\right)^{2}}
$$

where $n$ is the sample size per group, $\alpha$ is $0.05, \beta$ is $0.2, \sigma^{2}$ is the population variance in meantime union (standard deviation), $\mu_{1}$ is the population mean time to union in intramedullary nail without reaming, $\mu_{2}$ is the population mean time to union intramedullary with reaming, and $\mu_{1}-\mu_{2}$ is the minimum important difference to detect in population mean time to union between group 1 and group 2. Based on equation (1), all sample size for the EBS parameter is satisfied, whereas for the ENB parameter only satisfies one parameter.

The ovarian cancer patients have been hospitalized in RSUP Dr. Sardjito Hospital. The inclusion criteria of ovarian cancer patients are those whose age is in between 15 to 60 years old with a positive result of ovarian cancer is based on histopathological examination. The study has been approved by the Medical and Health Ethical Review Committee of the Faculty of Medicine, UGM, number: KE/FK/888/EC/2015 and all the patients gave their informed consent for the participation in the study. The patients have agreed to informed consent. Whereas, the exclusion criteria are patients who have a history of or are suffering from more than one type of cancer or any other diseases. Healthy subjects were those who have neither history of cancer nor recent sepsis and inflammation. Healthy subjects were not descendant from the cancer patient.

\section{B. Method}

This cross-sectional study was carried out in Dr. Sardjito Hospital and Biochemistry Laboratory, Faculty of Medicine, Universitas Gadjah Mada, Yogyakarta, Indonesia in May 2015 to December 2015. The cellular interaction pattern was observed by using the spectrophotometric method. Venousblood samples were obtained from ovarian cancer patients and healthy subjects. Three $\mathrm{mL}$ of venous blood was taken from each subject then filled into EDTA tubes: $1.0 \mathrm{~mL}$ for cellular interaction examination with the spectrophotometric method. The absorbance values were measured by spectrophotometry and observed every 4 seconds for 30 minutes. Two $\mathrm{mL}$ was used for patient routine monitoring.

From the graph of the pattern of absorbance versus the time, then obtained the parameters based on the energetics of non-biological system (ENBS) approach [15], [16], the researchers named the ENBS parameters. The value of the ENBS parameters is obtained from deterministic and stochastic analysis from the pattern of the absorbance versus the time. Furthermore, the new parameter is obtained from the ENBS parameter involving the cycle concept that is a characteristic of the living system [17], [18], the parameters based on the energetics of biological system (EBS) approach. This new parameter researchers name the EBS parameters. The t-test using programming in Matrix Laboratory (MATLAB) for Windows 7 tested the differences in ENBS and EBS parameters in the two groups. All $\mathrm{P}_{\text {value }}$ is statistically significant if it is below 0.01 . The receiver operating characteristic (ROC) curves were applied to evaluate the effect of biomarkers on these parameters. The area under the ROC curve (AUC) is used to evaluate the presence of biomarkers reflected in EOC with a correspondence interval (CI) of 95\%. The best cut-off value was determined based on the maximum sensitivity and specificity score as the optimal standard. Sensitivity and specificity value was calculated under the cut-off. The value AUC results were classified into excellent (AUC values of 0.9-1.0), good (AUC values of 0.8-0.9), fair (AUC values of $0.7-0.8$ ), poor (AUC values of 0.6-0.7), and failed (AUC values of $0.5-0.6)$ [19]. 


\section{RESULTS AND DISCUSSION}

Sixty-six subjects participated in this research. Healthy subjects consisted of 33 women, while ovarian cancer patients consisted of 33 women. The mean age of healthy subjects was 26.7 years old, while ovarian cancer patient was 45.9 years old. There were only 23 data available for staging and 25 data for chemotherapy. There were seven patients (stage I), three individuals (stage II), nine patients (stage III), and four patients (stage IV). For chemotherapy, 20 patients had chemotherapy; five patients did not have chemotherapy (Table I).

A purely deterministic basis cannot fully describe the complex biological systems as they often show nonlinear behavior. The pattern of EDTA-blood photo spectrum in time series data can is assessed using deterministic and stochastic approach. In this study, the deterministic and stochastic component is estimated by a quadratic equation. The baseline of the absorbance in time series data is estimated by the deterministic approach, whereas the random value of the absorbance is estimated by stochastic approach [20] using autocorrelation functions [21]. Data (or curve) fitting was carried out to determine the parameter value closest to the real data [22].
TABLE I

BASIC CHARACTERISTIC OF STUDY SUBJECT

\begin{tabular}{|l|l|r|}
\hline No. & \multicolumn{1}{|c|}{ Study group } & Number of Patients \\
\hline 1 & EOC patients & 33 \\
\hline 2 & Median age (range) & 49 \\
\hline 3 & Tumour staging & 23 \\
& a. Tumour stage I & 7 \\
& b. Tumour stage II & 3 \\
& c. Tumour stage III & 9 \\
& d. Tumour stage IV & 4 \\
\hline 4 & Chemotherapy & 25 \\
& < 1-time Chemotherapy & 5 \\
& $>$ 1-time Chemotherapy & 20 \\
\hline 5 & Healthy subjects & 33 \\
\hline 6 & Median age (range) & 24 \\
\hline
\end{tabular}

${ }^{\mathrm{d}}$ Denominator for $\%$ is a number of subjects of non-missing data for each category.

According to the results of the t-test, there were significant differences between EOC patients and healthy controls only in parameter-1 (IP1) of the parameters based on the ENBS approach. However, there were significant differences in all parameters based on the EBS (RP1-6) approach (Table II).

TABLE II

THE PARAMETERS OF PATTERn OF EDTA-BlOOd PHOTO SPECTRUM IN STUDY PARTICIPANTS BASED ON THE ENERGETICS OF NONBIOLOGICAL SySTEM (ENBS) AND ENERGETICS OF BIOLOGICAL SYSTEM (EBS) APPROACH

\begin{tabular}{|c|c|c|c|c|c|}
\hline \multirow[t]{2}{*}{ No. } & \multicolumn{5}{|c|}{ ENBS Approach } \\
\hline & Study group & $\mathbf{n}$ & IP1 & IP2 & IP3 \\
\hline 1 & EOC patients & 33 & $7.7 \mathrm{E}-11 \pm 6.7 \mathrm{E}-11$ & $-5.6 \mathrm{E}-05 \pm 4.9 \mathrm{E}-05$ & $4.9 \mathrm{E}+00 \pm 4.8 \mathrm{E}+00$ \\
\hline 2 & Healthy subjects & 33 & $-5.8 \mathrm{E}-13 \pm 1.4 \mathrm{E}-12$ & $3.9 \mathrm{E}-07 \pm 1.5 \mathrm{E}-06$ & $-7.1 \mathrm{E}-02 \pm 4.1 \mathrm{E}-01$ \\
\hline 3 & $\mathrm{P}$ & & $<0.01$ & $>0.01$ & $>0.01$ \\
\hline & & $\mathbf{n}$ & IP4 & IP5 & IP6 \\
\hline 4 & EOC patients & 33 & $1.2 \mathrm{E}-10 \pm 1.2 \mathrm{E}-10$ & $-8.9 \mathrm{E}-05 \pm 8.9 \mathrm{E}-05$ & $8.5 \mathrm{E}+00 \pm 8.2 \mathrm{E}+00$ \\
\hline 5 & Healthy subjects & 33 & $9.9 \mathrm{E}-13 \pm 2.7 \mathrm{E}-12$ & $-9.3 \mathrm{E}-07 \pm 2.5 \mathrm{E}-06$ & $-2.3 \mathrm{E}-02 \pm 5.2 \mathrm{E}-01$ \\
\hline 6 & $\mathrm{p}$ & & $>0.01$ & $>0.01$ & $>0.01$ \\
\hline \multicolumn{6}{|c|}{ EBS Approach } \\
\hline & & $\mathbf{n}$ & RP1 & RP2 & RP3 \\
\hline 7 & EOC patients & 33 & $1.4 \mathrm{E}-02 \pm 1.2 \mathrm{E}-03$ & $-1.3 \mathrm{E}-02 \pm 1.3 \mathrm{E}-03$ & $1.0 \mathrm{E}-02 \pm 1.7 \mathrm{E}-03$ \\
\hline 8 & Healthy subjects & 33 & $-3.7 \mathrm{E}-03 \pm 2.1 \mathrm{E}-03$ & $2.5 \mathrm{E}-03 \pm 2.5 \mathrm{E}-03$ & $-1.6 \mathrm{E}-03 \pm 2.1 \mathrm{E}-03$ \\
\hline 9 & $\mathrm{p}$ & & $<0.01$ & $<0.01$ & $<0.01$ \\
\hline & & $\mathbf{n}$ & RP4 & RP5 & RP6 \\
\hline 10 & EOC patients & 33 & $7.5 \mathrm{E}-03 \pm 4.1 \mathrm{E}-04$ & $-7.7 \mathrm{E}-03 \pm 5.1 \mathrm{E}-04$ & $8.7 \mathrm{E}-03 \pm 9.0 \mathrm{E}-04$ \\
\hline 11 & Healthy subjects & 33 & $3.1 \mathrm{E}-03 \pm 9.1 \mathrm{E}-04$ & $-3.7 \mathrm{E}-03 \pm 6.2 \mathrm{E}-04$ & $-3.6 \mathrm{E}-04 \pm 6.5 \mathrm{E}-04$ \\
\hline 12 & $\mathrm{p}$ & & $<0.01$ & $<0.01$ & $<0.01$ \\
\hline
\end{tabular}

IP: ideal parameter; RP: real parameter.

The AUC of parameters based on EBS approach is larger than the AUC of parameters based on the ENBS approach. The AUC of ENBS parameter was 0.663, 0.704, 0.546, $0.611,0.619$, and 0.676 and the AUC of EBS parameter was $0.886,0.855,0.765,0.909,0.897$, and 0.789 (Fig. 1, Table III).

TABLE III

THE PERFormance OF THE PARAMETERS OF PATTERN OF EDTA-BLOOD PHOTOSPECTRUM IN STUDY PARTICIPANTS BASED ON ENBS AND EBS APPROACH

\begin{tabular}{|c|c|c|c|c|c|c|}
\hline $\begin{array}{l}\text { Param } \\
\text { eters }\end{array}$ & AUC & SE & $95 \% \mathrm{CI}$ & $\begin{array}{c}\text { Sensi- } \\
\text { tivity } \\
(\%)\end{array}$ & $\begin{array}{l}\text { Speci- } \\
\text { ficity } \\
(\%)\end{array}$ & $\begin{array}{l}\text { Cut-off } \\
\text { point }\end{array}$ \\
\hline & & & & & & \\
\hline
\end{tabular}

\begin{tabular}{|l|l|l|l|l|l|l|l|}
\hline & & & LB & UB & & & \\
\hline \multicolumn{8}{|c|}{ ENBS Approach } \\
\hline IP1 & 0.663 & 0.068 & 0.530 & 0.797 & 48.5 & 100.0 & $1.0 \mathrm{E}-12$ \\
\hline IP2 & 0.704 & 0.066 & 0.575 & 0.832 & 42.4 & 100.0 & $-1.3 \mathrm{E}-06$ \\
\hline IP3 & 0.546 & 0.072 & 0.404 & 0.688 & 24.2 & 97.0 & $3.2 \mathrm{E}-01$ \\
\hline IP4 & 0.611 & 0.071 & 0.472 & 0.749 & 57.6 & 66.7 & $7.2 \mathrm{E}-11$ \\
\hline IP5 & 0.619 & 0.070 & 0.481 & 0.757 & 84.8 & 39.4 & $-2.7 \mathrm{E}-05$ \\
\hline IP6 & 0.676 & 0.067 & 0.544 & 0.808 & 60.6 & 72.7 & $4.5 \mathrm{E}+00$ \\
\hline \multicolumn{8}{|c|}{ EBS Approach } \\
\hline RP1 & 0.886 & 0.043 & 0.801 & 0.971 & 100.0 & 93.9 & $5.0 \mathrm{E}-04$ \\
\hline RP2 & 0.855 & 0.049 & 0.759 & 0.950 & 100.0 & 90.9 & $6.3 \mathrm{E}-04$ \\
\hline RP3 & 0.765 & 0.060 & 0.648 & 0.883 & 84.8 & 81.8 & $-1.1 \mathrm{E}-03$ \\
\hline RP4 & 0.909 & 0.039 & 0.833 & 0.985 & 100.0 & 100.0 & $9.4 \mathrm{E}-03$ \\
\hline RP5 & 0.897 & 0.041 & 0.816 & 0.978 & 100.0 & 97.0 & $-8.8 \mathrm{E}-03$ \\
\hline RP6 & 0.789 & 0.018 & 0.676 & 0.902 & 93.9 & 81.8 & $9.8 \mathrm{E}-03$ \\
\hline
\end{tabular}


Notes:

AUC: area under the ROC curve; SE: standard error; CI: confidence intervals; UB: Upper bound; LB: lower bound; ENBS: energetics of nonbiological systems; EBS: energetics of biological systems; IP: ideal parameter; RP: real parameter.

The AUC of parameter-4 is the largest in all of the parameters $(0.909, \mathrm{CI}: 0.833$ - 0.985). The parameters based on EBS approach had higher diagnostic efficiency than parameters based on the ENBS approach.

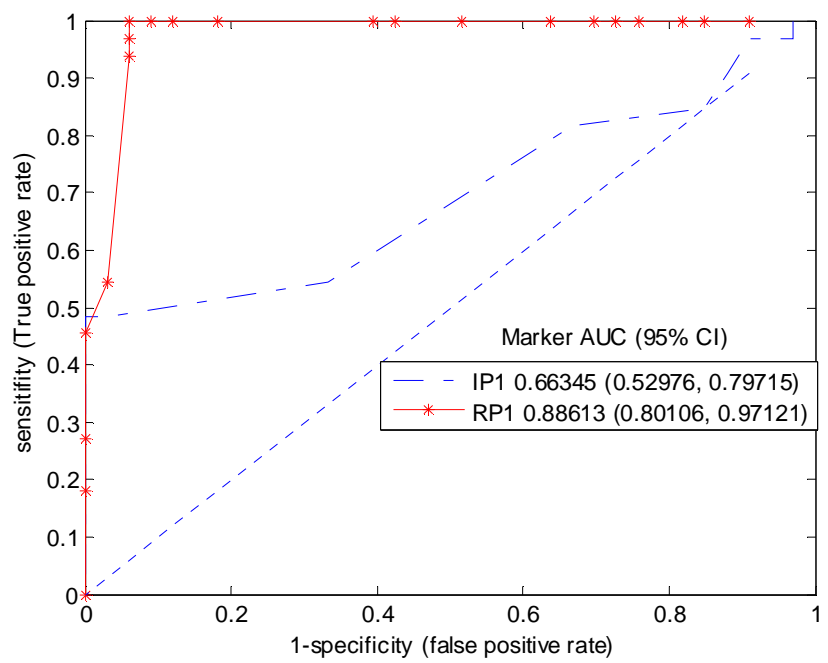

(a)

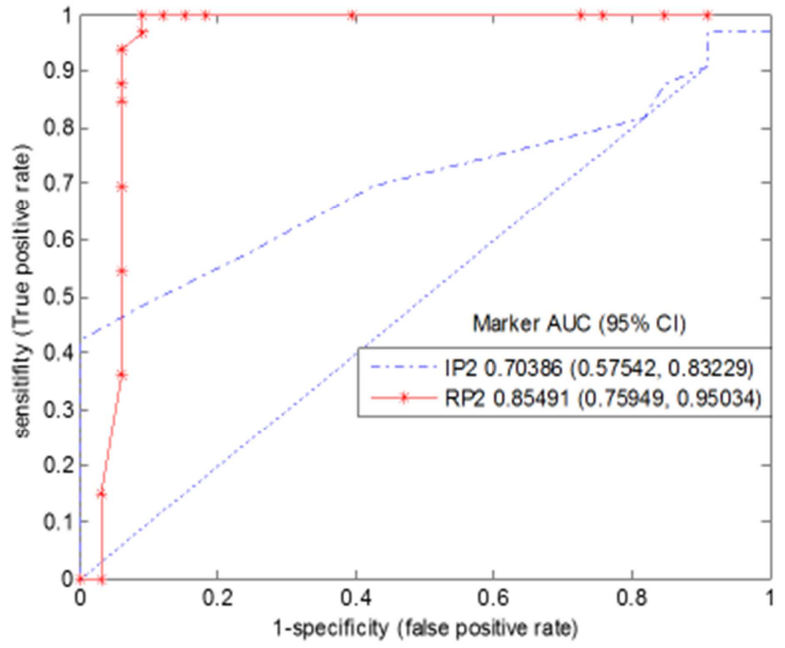

(b)

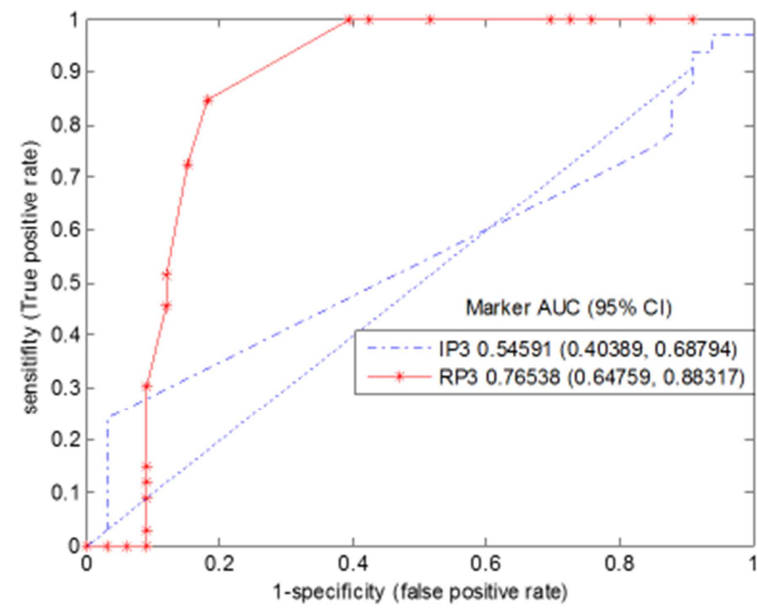

(c)

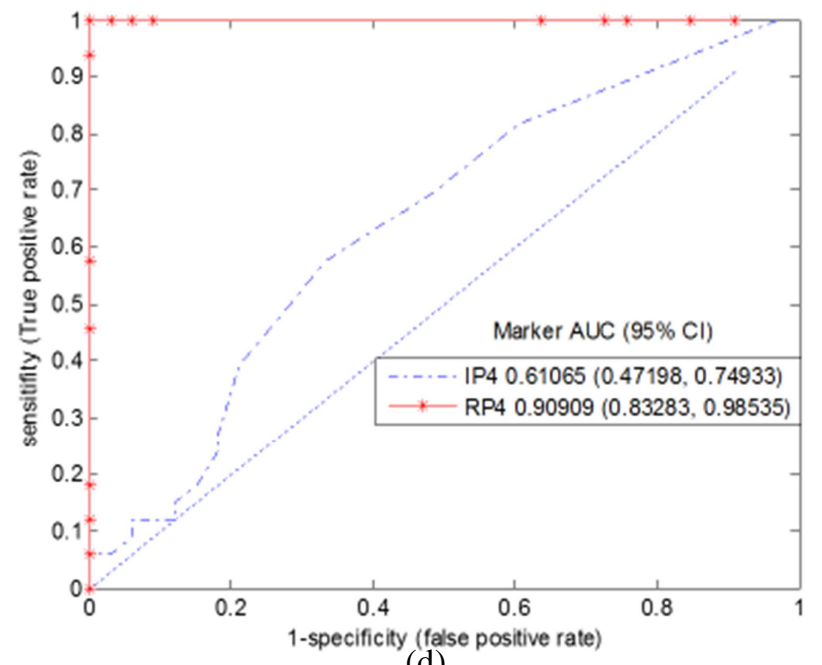

(d)

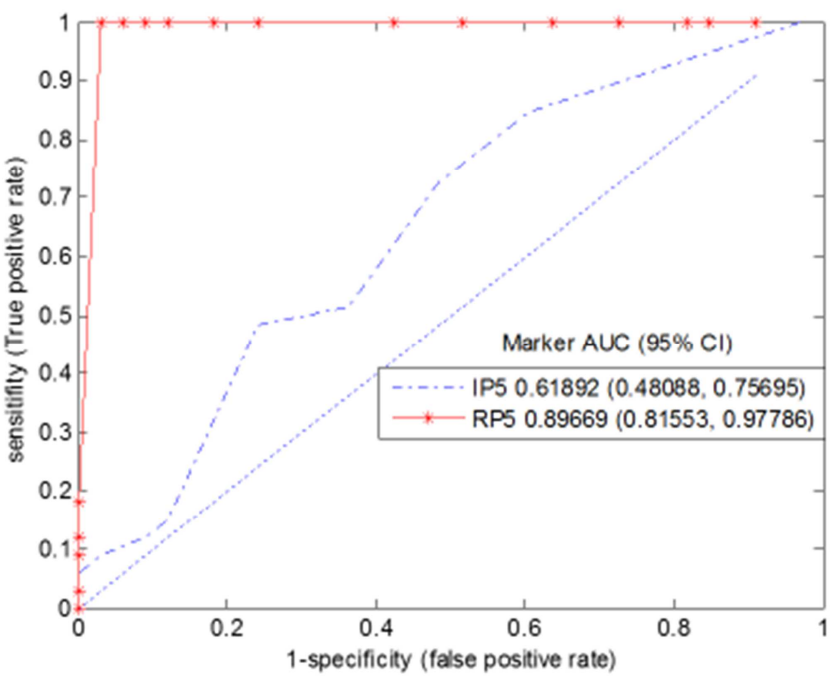

(e)

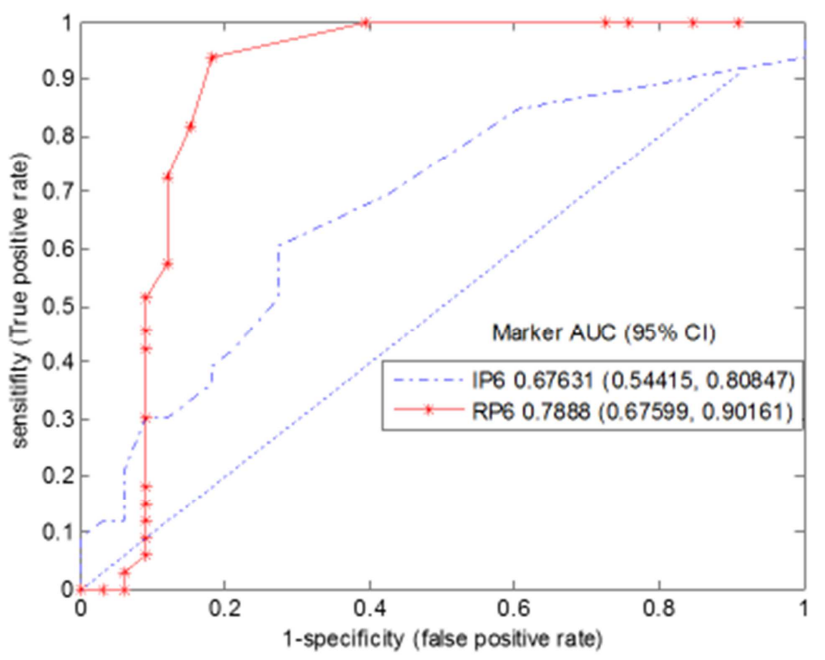

(f)

Fig. 1 ROC curves of parameters based on ENBS (ideal parameter, IP) and EBS approach (real parameter, RP) for EOC patients versus healthy controls, i.e.:(a)IP1,RP1; (b)IP2,RP2; (c)IP3,RP3; (d)IP4, RP4; (e)IP5, RP5; and(f)IP6, RP6. 
The most sensitive biomarker to see the response of patients after chemotherapy of ovarian cancer is CA125. CA125 is not very effective because it exists in both cancer patients and advanced-diseased patients. "CA125 increases only $50 \%$ of stage I EOC and $75 \%$ to $90 \%$ of patients with advanced disease" [23].CA125cannot distinguish early-stage EOC and normal individuals [24]. This is because, at very low concentrations, the presence of CA125 cannot be detected [25] - [27]. In addition, the cost of CA125 examinations is expensive [27], [28].

A new method is introduced to diagnose early-stage EOC by measuring the change of the erythrocyte sedimentation rate using the spectrophotometric method. As erythrocytes precipitates, plasma occupies the top region of the blood column. Macromolecules (rouleaux) were formed during the aggregation period when erythrocytes adhere together. Then the cells start to settle that can be monitored using the spectrophotometric method by calculating the water content of biological tissues in the upper region of the blood column in time series data [12].

In the early stages of cancer, the levels of proteins secreted as biomarkers are very low. The low level of biomarkers cannot be detected using the current method [25], [26]. The presence of biomarkers will change the zeta potential of erythrocyte (ZPE) in blood-EDTA [29], [30], so that it will affect the equilibrium of erythrocyte aggregation, such as the following:

$\mathrm{nE}<===>\mathrm{E}_{\mathrm{n}}(2)$

With $\mathrm{E}$ is erythrocyte and $\mathrm{n}$ is the number of erythrocytes. Based on Eq. 2, this method is effective because a small change in the concentration affects the absorbance change gradient at a particular time in the erythrocyte absorbance pattern. The markers change the Zeta potential value so that the aggregation and disaggregation rates change. This is because a biomarker is a protein. Every protein consists of amino acid residue with different composition or sequence. A different amino acid residue sequence causes a different tertiary structure because of foldering. Each amino acid has a specific acid balance. Hence, it affects a specific value of the Zeta potential. Overall, this may change the erythrocyte absorbance pattern. Furthermore, this method is efficient because it only uses EDTA, and no reagent is needed, whereas other methods (CA125) need specific antibody and enzyme.

In equation (2) if the equilibrium shifts to the right, it will produce a decreasing absorbance reading, whereas if the equilibrium shifts to the left, it will increase absorbance readings [31]. When equilibrium occurs, it will produce a constant absorbance reading. Thus, the existence of biomarkers will influence the pattern of absorbance patterns with time.

Biomarkers affect the balance of erythrocyte aggregation, when the balance shifts to the right, erythrocyte aggregation occurs; conversely, if the balance shifts to the left, erythrocyte disaggregation occurs. In this study, the type of aggregation and the repetition of aggregation in EOC patients differed from those in healthy controls (Fig. 2-4 and Table III, IV). Repetition of aggregation in patients in the EOC group which were not found in the normal group was 14 types of aggregate from total of 87 aggregates, i.e.: aggregate- 1 to 14 each $10,23,16,8,14,4,3,2,1,2,1,1,1$, and 1. In normal group which was not found in the EOC group was seven types aggregate from the total of 124 disaggregate. There are both EOC and normal group $=55$ aggregates. Repetition of disaggregation in patients in the EOC group which were not found in the normal group was ten types from the total of 115 disaggregate, and in normal group which was not found in EOC group was nine types of disaggregate from a total of 104 disaggregate. There are both EOC and normal group $=72$ disaggregate.

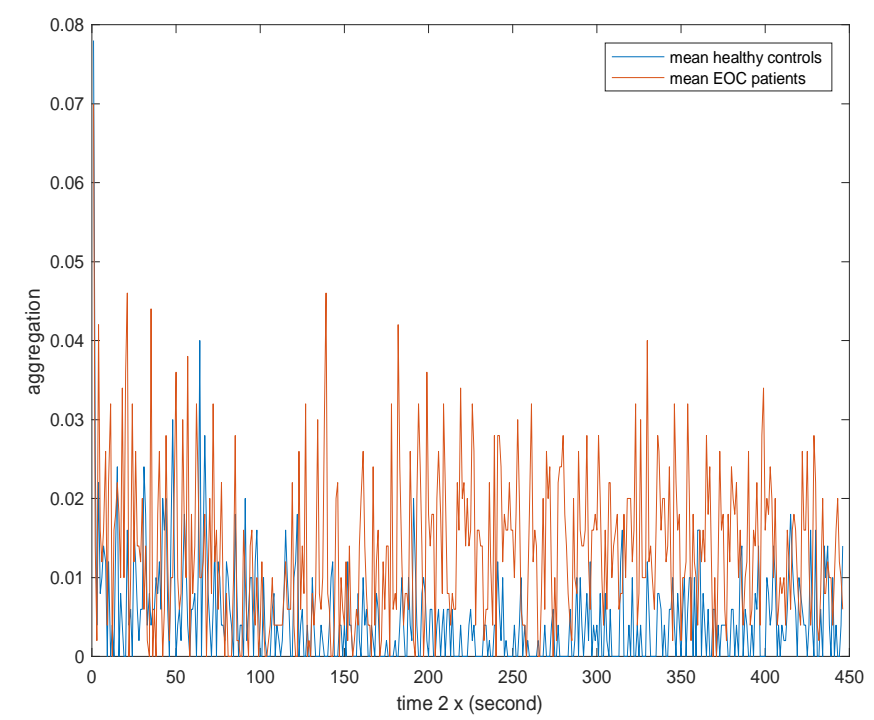

(a)

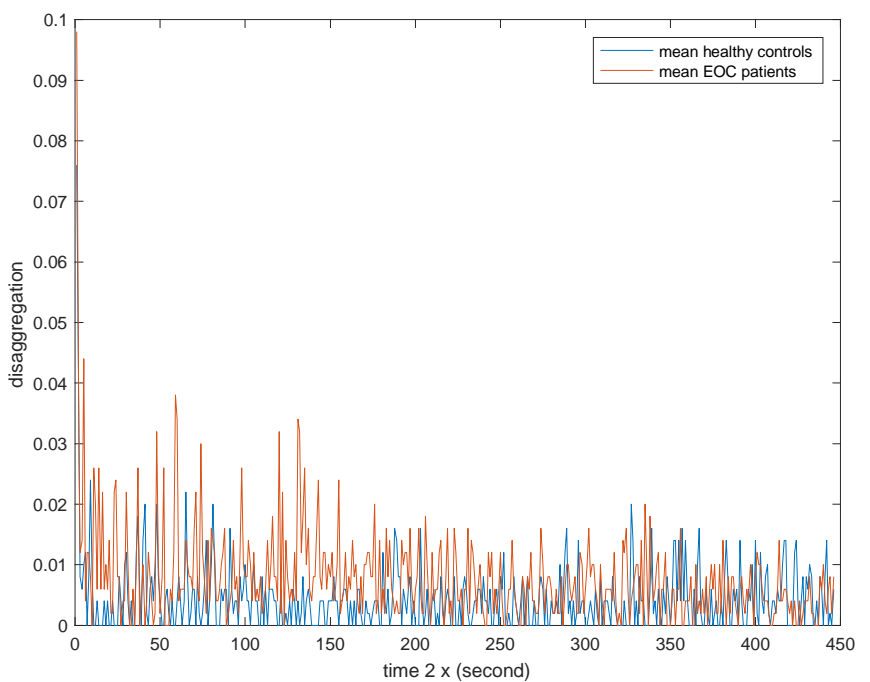

(b)

Fig. 2 Biomarker fingerprints in time series data of absorbance of EDTAblood EOC patients and healthy controls. (a. Aggregation; b. disaggregation)

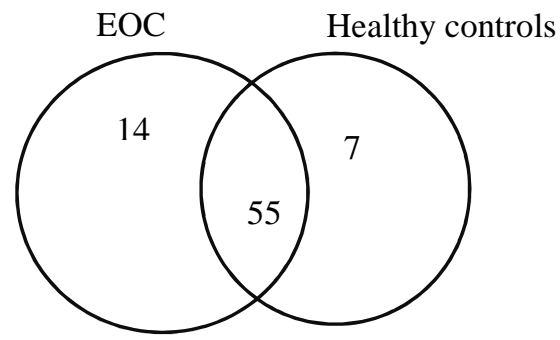

Fig. 3 Type and repetition of erythrocyte aggregation of EDTA-blood in EOC patients and healthy controls; 14 (87): 14 types of aggregate from a total of 87 aggregate; 7 (124): 7 types of aggregate from a total of 124 aggregates; 
EOC patients Healthy controls

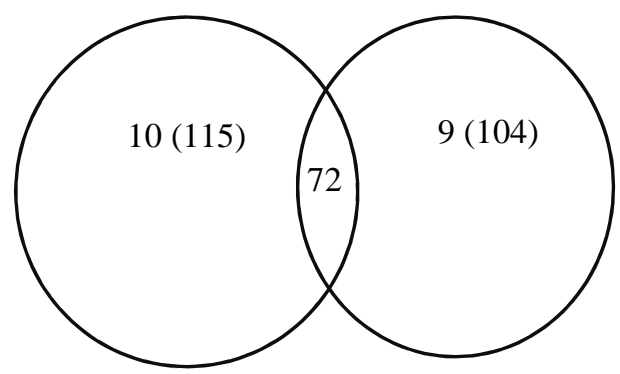

Fig. 4 Type and repetition of erythrocyte disaggregation of EDTA-blood in EOC patients and healthy controls; 10 (115): 10 types of disaggregate from 115 disaggregates; nine (104): nine types of disaggregate from 104 disaggregates.

TABLE IV

ERYTHROCYTE AGGREGATION OF EDTA-BLOOD IN EOC PATIENTS AND NORMAL SUBJECTS

\begin{tabular}{|c|c|c|c|c|}
\hline \multirow[b]{2}{*}{ 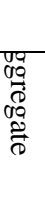 } & \multicolumn{2}{|c|}{ Group I } & \multicolumn{2}{|c|}{ Group II } \\
\hline & $\begin{array}{l}\bar{\sigma} \\
0 \\
0 \\
0 \\
\stackrel{0}{0} \\
0\end{array}$ & 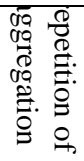 & 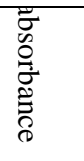 & 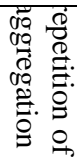 \\
\hline 1 & 0.031 & 10 & 0.059 & 31 \\
\hline 2 & 0.063 & 23 & 0.118 & 28 \\
\hline 3 & 0.094 & 16 & 0.176 & 34 \\
\hline 4 & 0.125 & 8 & 0.235 & 20 \\
\hline 5 & 0.156 & 14 & 0.294 & 6 \\
\hline 6 & 0.188 & 4 & 0.412 & 4 \\
\hline 7 & 0.219 & 3 & 0.529 & 1 \\
\hline 8 & 0.25 & 2 & & \\
\hline 9 & 0.281 & 1 & & \\
\hline 10 & 0.313 & 2 & & \\
\hline 11 & 0.375 & 1 & & \\
\hline 12 & 0.406 & 1 & & \\
\hline 13 & 0.438 & 1 & & \\
\hline 14 & 0.625 & 1 & & \\
\hline
\end{tabular}

The detection method in this study has no side effects because the examination only uses blood samples. Thus, the method in this study can replace the CA125 examination method. Before the occurrence of cancer, a random mutation happens, which produces various kinds of biomarkers, i.e., not only CA125. All of these biomarkers affect the erythrocytes such that they affect the photo spectrum pattern of the EDTA-blood.

Statistically, time-series signals in the form of photospectrum are discerned into deterministic and stochastic components. In a prediction setting, the occurrence of the stochastic system degrades the deterministic portion of the signal. The portion of the predictable variance equals the variance of the deterministic component. In this report, the component of the signal that can be predicted from several previous time samples functions as the basis for the deterministic component, whereas the component for which such prediction is impossible determines the stochastic components. To analyze the pattern of EDTA-blood photo spectrum as time-series data, we used the deterministic and stochastic approach based on ENBS and EBS [32], [33].In this study, the deterministic and stochastic component is estimated by a quadratic equation, whereas autocorrelation functions estimate the stochastic component. These two estimates were carried out by fitting the data (or curve) to determine the parameter values that most closely match the data.

TABLE V

ERYTHROCYTE DISAGGREGATION OF EDTA-BLOOD IN EOC PATIENTS AND NORMAL SUBJECTS

\begin{tabular}{|c|c|c|c|c|}
\hline & \multicolumn{2}{|c|}{ Group I } & \multicolumn{2}{|c|}{ Group II } \\
\hline 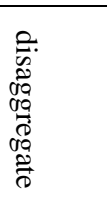 & 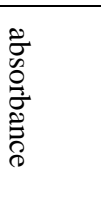 & 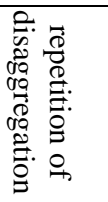 & 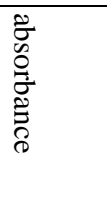 & 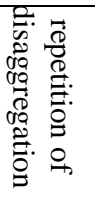 \\
\hline 1 & 0.031 & 24 & 0.059 & 31 \\
\hline 2 & 0.063 & 32 & 0.118 & 38 \\
\hline 3 & 0.094 & 19 & 0.176 & 12 \\
\hline 4 & 0.125 & 16 & 0.235 & 8 \\
\hline 5 & 0.156 & 5 & 0.294 & 6 \\
\hline 6 & 0.188 & 2 & 0.353 & 5 \\
\hline 7 & 0.219 & 9 & 0.412 & 2 \\
\hline 8 & 0.25 & 5 & 0.471 & 1 \\
\hline 9 & 0.313 & 2 & 0.529 & 1 \\
\hline 10 & 0.344 & 1 & & \\
\hline
\end{tabular}

Overall, the value of sensitivity and specificity can be used to identify the quality of a method, in this case, a method for detecting biomarkers. In this study, the sensitivity and specificity of the ENBS approach were low (average $=53.0$ and 79.3, respectively). While the sensitivity and specificity of the EBS approach are higher (average = 96.5 and 90.9, respectively). (Figure 1, Table III). This shows that the use of the EBS approach to detect biomarkers that affect cellular interactions in EDTA-blood from research subjects is better than the ENBS approach. Thus, it can be concluded that to detect the presence of biomarkers in EOC patients, it is better to use the EBS approach compared to using the ENBS approach. From Figure 1 and Table III, it is also seen that the AUC value based on the ENBS approach is low (average $=0.637$ ). This shows that with the ENBS approach; the presence of biomarkers in blood plasma that affect ZPE [34] is less detectable. While the AUC value based on EBS is higher (average= 0.850), which shows that with the EBS approach, the presence of biomarkers can be detected [19, from the following table, can be seen from the highest AUC value in parameter four based on EBS approach $(=0.909)$. The values of sensitivity and specifications are based on Table 3 in the columns of specify and sensitivity. This shows that the presence of biomarkers 
was detected very well by analyzing the pattern of EDTAblood photos spectrum in EOC patients based on ENBS approach on parameter 4 (RP4). All available markers (not only CA125) give specific absorbance patterns. Compared with CA125, the sensitivity and specificity of parameters based on EBS approach were higher than CA125 (100\% and $100 \%$ for RP4; $72.7 \%$ and $64.5 \%$ for CA125) [35].

Compared with previous research, this research is more convincing. First, data that is more comprehensive is presented in this study for diagnostic research, such as cutoff values, sensitivity, and specificity. Second, this research is the first study on cancer detection without isolating biomarkers. Biomarkers in EDTA-blood affect cellular interactions, through ZPE changes when viscosity dispersion and dielectrics are permitted to be included and applied to Smoluchowski theory [36]. Thus, the smallest biomarker level will be detected using this method. Before the occurrence of cancer, the presence of one or more mutations that trigger tumor growth will affect the composition of proteins in blood plasma, which will affect ZPE. Therefore, with this method, the biomarkers of EOC patients will be detected.

From this study, new parameters were found that could be used as diagnostic tools to identify the presence of EOC, the values of all parameters based on the EBS approach differed significantly between EOC patients and healthy controls $(\mathrm{p}=$ 2.65E-25, 3.16E-21, 1.28E-03, 7.62E-37, 5.39E-28, 1.49E05 for real parameter-1to 6). The ROC curve analysis showed that the predictive ability of EBS parameters as a biomarker reflection of EOC was better than CA125. Senility and specificity for EBS parameters $=100.0 \%$, $100.0 \%, 84.8 \%, 100.0 \%, 100.0 \%$, and $93.9 \%$; and $93.9 \%$, $90.9 \%, 81.8 \%, 100.0 \%, 97.0 \%$, and $81.8 \%$ respectively; while sensitivity and specificity for CA125 $=72.7 \%$ and $64.5 \%$ respectively [35] (Table III). The effectiveness of this method is in expensive, and the only sample needed is blood. Furthermore, the high sensitivity and specificity of this method show its efficiency.

\section{CONCLUSION}

We have succeeded in discovering a new method for detecting biomarkers secreted by cancer cells in EOC patients. This method is applied by analyzing the patterns of absorbance in EDTA-blood, which is based on the concept of EBS to determine the parameters that indicate the presence of biomarkers from EOC patients. This method can replace the CA125 examination because this method has greater sensitivity and specificity than CA125 examination.

\section{ACKNOWLEDGMENT}

The authors gratefully thank Damas Research Grant 2015 for financial support in the study. Special thank is also expressed for Prof. Adhi Susanto, MSc., PhD. from the Department of Electrical Engineering Faculty of Engineering, Universitas Gadjah Mada, Yogyakarta for interpreting the signal analysis of time series data.

\section{REFERENCES}

[1] J. Krzystyniak, L. Ceppi, D. S. Dizon, and M. J.Birrer, Epithelial ovarian cancer: the molecular genetics of epithelial ovarian cancer. Annals of Oncology, vol. 27(Supplement 1), pp. i4-i10, Apr. 2016.

[2] Berek J S, Crum C, and Friedlander M., Cancer of the ovary, fallopian tube, and peritoneum. Int J Gynecol Obstet, vol. 119 suppl2, pp. s118-s129, oct.2012.

[3] M. F. Aziz, Gynecological cancer in Indonesia. J Gynecol Oncol, vol. 20(1), pp. 8-10, Marc.2009.

[4] E. Kobayashi, Y. Ueda, S. Matsuzaki, T. Yokoyama, T. Kimura, K. Yoshino, M. Fujita, T. Kimura, and T. Enomoto, Biomarker for Screening, Diagnosis, and Monitoring of Ovarian Cancer.American Association for Cancer Research, vol. 12, pp. 1902-1912, Sept. 2012.

[5] M. Felder, A. Kapur, J. Gonzalez-Bosquet, S. Horibata, J. Heintz, R. Albrecht, L. Fass, J. Kaur, K. Hu, H. Shojaei, R. J. Whelan, and M. S. Patankar, MUC16 (CA125): Tumor Biomarker to Cancer Therapy, a Work in Progress.Molecular Cancer, vol. 13, pp. 1-15, 2014.

[6] S. Polterauer, C. Grimm, V. Seebacher, N. Concin, C. Marth, C. Tomovski, H. Husslein, H. Leipold, K. Hefler-frischmuth, C. Tempfer, A. Reinthaller, and L. Hefler, Plasma fibrinogen levels and prognosis in patients with ovarian cancer: a multicenter study. Oncologist, vol. 14(10), pp. 979-85, Oct. 2009.

[7] Kumta, G. Nayak, H. P. Kedilaya, and M. Shantaram, A Comparative Study of Erythrocyte Sedimentation Rate (ESR) Using Sodium Citrate and EDTA. International Journal of Pharmacy and Biological Sciences, vol. 1, pp. 393-396, Oct.-Des. 2011.

[8] O. K. Baskurt, and H. J. Mesiselman, Erythrocyte Aggregation: Basic Aspect and Clinical Importance.Clinical Hemorheology and Microcirculation, 53, pp. 23-37, 2013.

[9] S. P. Ballou, and I. Kushner, Laboratory Evaluation of Inflammation. In: W. N. Kelley, E. D. Jr. Harris, S. Ruddy, C.B. Sledge, editors. Textbook of Rheumatology, $4^{\text {th }}$ ed, Philadelphia: W.B. Saunders Co., 1993.

[10] E. Brahn, C.D. Scoville, Biochemical Markers of Disease Activity. In: H. Bird, J.S. Dixon, editors. Biochemical Aspects of Rheumatic Diseases. Vol. 2. London: Bailliere Tindall; 1988.

[11] F. Tas, and K. Erturk, 2017. The elevated erythrocyte sedimentation rate is associated with metastatic disease and worse survival in patients with cutaneous malignant melanoma. Molecular and Clinical Oncology, vol. 7, pp. 1142-1146. Oct. 2017.

[12] Ngadikun, "Pengukuran Laju Endap Darah (Erythrocyte Sedimentation Rate) dengan Metode Spektrometri," M. Bio. Med. thesis, Indonesia University, Jakarta, June 1998.

[13] S.K. Hahl, and A. Kremling, A comparison of deterministic and stochastic modeling approaches for biochemical reaction systems: on fixed points, means, and modes. Front. Genet, vol. 7, pp. 157, Aug. 2016.

[14] F. Farrokhyar, D. Reddy, R.W. Poolman, and M. Bhandari, why perform a priori sample size calculation? Can J surg, vol. 56, pp. 207-213 June. 2012.

[15] I.J. Ford, Measures of thermodynamic irreversibility in deterministic and stochastic dynamics. New J. Phys., vol. 17, pp. 1-22, Aug. 2015.

[16] A. C. Barato, and U. Seifert, Cost and Precision of Brownian Clocks. Physical Review X, vol. 6, pp. 041053-1 - 041053-14, Dec. 2016.

[17] L.F. del Castillo, and P. Vera-Cruz, 2011. Thermodynamic formulation of living systems and their evolution. Journal of Modern Physics, vol.2, pp. 379-391, May 2011.

[18] S. Huang, F. Li, J.X. Zhou, H. Qian, Processes on the emergent landscapes of biochemical reaction networks and heterogeneous cell population dynamics: differentiation in living matters. Journal of TheRoyal Society Interface, pp.1-35, June 2017

[19] L. Ludemann, W. Grieger, R. Wurm, P. Wust, C. Zimmer, Glioma assessment using quantitativeblood volume maps generated by T1weighted dynamic contrast-enhanced magnetic resonanceimaging: a receiver operating characteristic study. Acta Radiol, vol. 47, pp. 30310, Apr. 2006.

[20] F. Mazzocchi, Complexity in biology: Exceeding the limits of reductionism and determinism using complexity theory. EMBO reports, vol. 9 (1), pp. 10-4,Jan. 2008.

[21] G. D. Durgin, Theory of Stochastic Local Area Channel Modeling For Wireless Communications. Final Dissertation submitted to the Faculty of the Virginia Polytechnic Institute and State University, 2000 
[22] A. J. Brown, Spectral curve fitting for automatic hyperspectral data analysis. IEEE Trans Geosci Rem Sens, vol. 44, pp. 1601-08, 2006.

[23] H.A. Fritsche, R.C. Bast, CA125 in ovarian cancer: advances and controversy. Clin Chem., vol. 44, pp. 1379-80, Juli. 1998.

[24] L. Fan, M., Yin, C. Ke, T. Ge, G. Zhang, W., W. Zhang, X. Zhou, G. Lou, and K. Li, Use of Plasma Metabolomics to Identify Diagnostic Biomarkers for Early Stage Epithelial Ovarian Cancer, Journal of Cancer, vol. 7, pp. 1265-1272, Jun 2016

[25] M. J. Duffy, J. M. Bonfrer, J. Kulpas, G. J. S. Rustin, G. Soletormos, G. C. Torre, M. K. Tuxen, and M. Zwirner, CA125 in ovarian cancer: European Group on Tumor Markers guidelines for clinical use. Int $J$ Gynecol Cancer, vol. 15, pp. 679-691, Sept. 2005.

[26] R. T. Fortner, A. F. Vitonis, H. Schock, A. Hüsing, T. Johnson, R. N. Fichorova, T. Fashemi, H. S. Yamamoto, A. Tjønneland, L. Hansen, K. Overvad, M. Boutron-Ruault, M. Kvaskoff, G. Severi, H. Boeing, A. Trichopoulou, V. Benetou, C. La Vecchia, D. Palli, S. Sieri, R. Tumino, G Matullo, A. Mattiello, N. C. Onland-Moret, P. H. Peeters, E. Weiderpass, I. T. Gram, M. Jareid, J. R. Quirós, E. J. Duell, M.Sánchez, M. D. Chirlaque, E. Ardanaz, N. Larrañaga, B. Nodin, J. Brändstedt, A. Idahl, K. Khaw, N. Allen, M. Gunter, M. Johansson, L. Dossus, M. A. Merritt, E. Riboli, D. W. Cramer, R. Kaaks, and K. L. Terry Correlates of circulating ovarian cancer early detection markers and their contribution to discrimination of early detection models: results from the EPIC cohort,Journal of Ovarian Research, vol.10, pp. 1-14, March 2017.

[27] A. Gazze,R. Ademefun, R. S. Conlan, and S. R Teixeira, Electrochemical impedence spectroscopy enabled CA125 detection; toward early ovarian cancer diagnosis using graphene biosensors. Journal of Interdisciplinary Nanomedicine, vol. 3(2) 2018, 3 (2), pp. 82-88, May 2018.

[28] S. Sakamoto, W. Putalun, S. Vimolmangkang, W. Phoolcharoen, Y. Shoyama, H. Tanaka, and S. Morimoto, Enzyme-linked immunosorbent assay for the quantitative/qualitative analysis of plant secondary metabolites. Journal of Natural Medicines, vol. 72, pp. 32-42, Nov. 2018.
[29] L. Landgraf, C. Christner, W. Storck, I. Schick, I. Krumbien, H Dähring, K Haedicke, K. Heinz-Herrman, U. Teichgräber, J. R. Reichenbach, W. Tremel, S. Tenzer, and I. Hilger, A plasma protein corona enhances the biocompatibility of $\mathrm{Au} @ \mathrm{Fe}_{3} \mathrm{O}_{4}$ Janus particles. Biomaterials, vol.68, pp.77-88, Aug. 2015

[30] L. K. Müller, J. Simon , S. Schüttler , K. Landfester, V. Mailänder, and K. Mohr, Pre-coating with protein fractions inhibits nano- carrier aggregation in human blood plasma. RSC Adv., vol. 6, pp. 9649596509. Sept. 2016

[31] K. A. Nugroho, K. Abraha , and Ngadikun, The Mechanism of Erythrocytes Aggregation in EDTA-Blood of Ovarian Cancer Patients Viewed by Coulomb's Law. IJASEIT, vol. 7 (6), pp. 2175 2182, S3pt. 2017.

[32] Higgins JP. Nonlinear systems in medicine. Yale J Biol Med., vol. 75(5-6), pp.247-60, Sep-Dec. 2002.

[33] J. A Rioux, complex, nonlinear dynamic systems perspective on ayurveda and ayurvedic research. JTCM,vol. 18(7), pp. 709-18, Juli. 2012.

[34] G. Chevalier, S. T. Sinatra, J. L. Oschman, and R. M.Delany, Earthing (grounding) the human body reduces bloodviscosity-a major factor in cardiovascular disease. J Altern Complement Med., vol. 19(2), pp. 102-110, Feb. 2013.

[35] . Wu, H. Yin, J. Zhu, J. Ronald, R.J. Buckanovich, J. D. Thorpe, J Dai, N. Urban, and D. M. Lubman, Validation of LRG1 as a potential biomarker for detection of epithelial ovarian cancer by a blinded study. PLoS One., vol. 2009, pp. 1-11, March. 2015.

[36] A. Sze, D. Erickson, L. Ren, and D. Li, Zeta-potential measurement using the Smoluchowski equation and the slope of the current-time relationship in electroosmotic flow. J. Colloid Interface Sci.,vol. 261, pp.402-10, May. 2003. 